\title{
EVOLUCIÓN DEL ESTADO AUTONÓMICO Y REFORMA DE LOS ESTATUTOS
}

\author{
VICENTE GARRIDO MAYOL \\ Profesor Titular de Derecho \\ Constitucional \\ Consejero del Consejo Jurídico \\ Consultivo de la Comunidad Valenciana
}





\title{
EVOLUCIÓN DEL ESTADO AUTONÓMICO Y REFORMA DE LOS ESTATUTOS 1
}

POR

\author{
VICENTE GARRIDO MAYOL \\ Profesor Titular de Derecho Constitucional \\ Consejero del Consejo Jurídico Consultivo \\ de la Comunidad Valenciana
}

En un curso que se titula "Reforma Constitucional, autodeterminación y modelo de Estado", y en el que voy a hablar sobre la evolución del Estado Autonómico y la reforma de los Estatutos, creo oportuno comenzar recordando algo que con frecuencia se olvida, y que conviene tener bien presente para comprender muchas de las cuestiones relacionadas con nuestra particular forma territorial de Estado que, aún hoy, tras más de veinte años de vigencia de la Constitución, ocupan nuestra atención. $Y$ es que una de las notas que han caracterizado la historia política de España ha sido la del secular conflicto acerca de la configuración del Estado, la de su organización territorial, consecuencia de la primitiva existencia de varios pueblos originarios, diferenciados entre sí, con características geográficas, económicas, culturales y sociales distintas, que la uniformidad que sucede a la unidad

1 Texto ampliado de la conferencia pronunciada en el curso «Reforma constitucional, autodeterminación y modelo de Estado", organizado por la UNED bajo la dirección del Prof. Antonio Torres del Moral. Ávila, 14 de julio de 1999. 
desdibuja, tratando de imprimir a todos los pueblos integrados en el nuevo Estado la única caracterización.

Desde luego, ha habido intentos de dar solución a ese problema que de forma permanente nos ha acompañado en nuestra historia constitucional. Dejando aparte los proyectos descentralizadores del S. $\mathrm{XIX}$, incluso el del Estado Federal de la Constitución "non nata" de 1873, el legislador constituyente de 1931 así lo pretendió, definiendo a España como un Estado integral, intermedio entre el Estado unitario y el Estado federal -al decir de Jiménez de Asúa, a la sazón Presidente de la Comisión Legislativa encargada de dictaminar el texto constitucional -2 , caracterizado de tal forma que se convertiría en un importante punto de referencia fuera de las fronteras españolas 3 .

Pero el truncamiento del orden constitucional nacido el 9 de diciembre de 1931, imposibilitó el desarrollo de las previsiones constitucionales, quedando el viejo problema regional, de nuevo, irresoluto.

La existencia de ese problema justificó que el legislador de 1978 le prestara especial atención, reconociendo a los pueblos españoles - regiones y nacionalidades, en terminología constitucional--, el derecho a constituirse en Comunidades autónomas.

Pero hoy, cuando han transcurrido más de veinte años de vigencia de la Constitución de 1978, la cuestión autonómica sigue constituyendo uno de los grandes temas de Estado, objeto de controversia permanente, y parece que perpetua, que separa a gobernantes, partidos políticos y ciudadanos en general, y objeto también de atención preferente por los constitucionalistas, como lo pone de manifiesto la celebración de este curso.

2 «La antítesis del Estado unitario-Estado federal -dijo Jiménez de Asúa-, exige hay su superación, por una síntesis de Estado integral». Y ańadía: "Deliberadamente no hemos querido decir en nuestra Constitución que España es una República Federal; no hemos querido declararlo porque hoy, tanto el unitarismo como el federalismo están en franca crisis teórica y práctica. Sirva de ejemplo el caso de Alemania... El Estado federal alemán va transformándose en Estado integral. No hemos querido, además, hacer uso del término federal porque federar es unir. Se han federado aquellos paises que vivieron dispersos y que, más tarde, quisieron vivir en régimen colectivo. El caso de España es inverso: Estado unitario hasta ahora, varias de sus regiones, pretenden autonomía...". Vid. en "Diario de Sesiones de las Cortes constituyentes de la República Española». 27 agosto 1931, págs. 644-645.

3 L. VANOELLI, "El ordenamiento español de las Comunidades Autónomas". Madrid, 1982, pág. 43. 
Es verdad, como se ha dicho, que nuestra Constitución ni proclama a España como un Estado autonómico, ni define lo que éste pueda ser, ni tan siquiera diseña o configura lo que hoy es una realidad. Pero la propia historia de España y la dinámica política observada durante la transición a la democracia anunciaban que el Estado habia de abandonar la estructura centralista para dar paso al reconocimiento del derecho al autogobierno de los distintos pueblos que en el pasado gozaron del mismo.

- La propia historia de España, porque nos pone de manifiesto que el Estado autonómico no es una creación caprichosa de los políticos ni, simplemente, la estructuración interna del poder para lograr una gestión más eficaz, sino, sobre todo, la respuesta a un problema latente y constante desde que se inició, en los albores del S. XIX, nuestro régimen constitucional.

Quizás convenga recordar, con Ortega y Gasset, que la historia de toda nación, y sobre todo de la nación latina, es un vasto sistema de incorporación. Una incorporación que no es la dilatación de un núcleo inicial sino más bien la organización de muchas unidades sociales preexistentes en una nueva estructura. Pero el núcleo inicial -observaba Ortega-, ni se traga los pueblos que va sometiendo, ni anula el carácter de unidades vitales propias que antes tenían. Palabras, las de Ortega, que quizás sirvan para explicar la razón del proceso autonómico español4.

- Y la dinámica política de la transición a la democracia, porque anunciaba la nueva forma de Estado, al constituirse, como solución de emergencia a las reivindicaciones autonomistas, los regímenes preautonómicos - prolegómeno de lo que serían las posteriores comunidades autónomas-, aunque hay que reconocer que entonces, ni los nacionalistas más optimistas imaginaban unas nacionalidades y regiones con el grado de autonomía hoy alcanzado.

Pero pronto se vio que el Estado autonómico, como forma de Estado muy cercana al esquema federal y cuyo antecedente remoto es genuinamente español -la Constitución republicana de 1931-, no era un modelo cerrado sino en constante proceso de configuración.

Hay que recordar que nuestra Carta Magna de 1978 no constitucionaliza como forma territorial la que hoy ofrece el Estado español

4 J. Ortega y Gasset, España invertebrada, Espasa Calpe, Madrid, 1980, pág. 35. 
- se ha hablado, acertadamente, de que la formula constitucional es la de un "Estado regionalizable"-, y que consagra el principio dispositivo -en virtud del cual la autonomía es un derecho pero no una obligación, y el grado de aquélla puede ser diferente por voluntad de las Comunidades Autónomas-, que hay que conjugar con las previsiones del art. $144 \mathrm{c}$ ) de la $C E$ - que faculta a las Cortes Generales para que, por motivos de interés nacional, puedan sustituir por medio de Ley Orgánica, la iniciativa de las Corporaciones Locales a que se refiere el art. 143.2 CE-, y con lo dispuesto en el art. 150.2 CE-, según el cual el Estado puede transferir o delegar a las Comunidades Autónomas, por Ley Orgánica, facultades correspondientes a materia de titularidad estatal que por su propia naturaleza sean susceptibles de transferencia o delegación-.

$Y$ tales principios y previsiones se han observado, con mejor o peor fortuna, en un proceso autonómico delimitado por grandes etapas: la aprobación de los Estatutos de País Vasco, Cataluña y Galicia; el referéndum andaluz y la medida excepcional adoptada para constituir esta Comunidad Autónoma; los Pactos autonómicos de 1981; la aprobación de los demás Estatutos de autonomía, también con medidas excepcionales en los casos de Comunidad Valenciana y Canarias, a fin de que desde el inicio, y pese a su acceso a la autonomía por la vía del art. 143 de la Constitución, pudieran contar con el máximo grado de autonomía posible5; y en el caso de Castilla-León, para que la provincia de Segovia quedara incorporada a esta Comunidad Autónomá; la reforma "teledirigida" de siete Estatutos de autonomía, en 1991, a fin de unificar la fecha en que debían celebrarse sus elecciones autonómicas; los pactos autonómicos de 1992 y la subsiguiente transferencia de competencias a las Comunidades del 143, hasta su asunción estatutaria mediante las reformas operadas en 1994; la aprobación de los Estatutos de Ceuta y Melilla, en 1995; la reforma de los Estatutos de Canarias y Aragón un año después; la del de Castilla-La Mancha, en 1997; la de los Estatutos de Murcia, Madrid y Cantabria, en 1998; y las más recientes de los de Asturias, Rioja, Baleares, Castilla-León y Extremadura, ya en

5 Para ello, simultáneamente a la aprobación de sus Estatutos de autonomía, se promulgaron, al amparo de lo dispuesto en el art. 150.2 de la Constitución, las Leyes Orgánicas 11 y 12 de 1982, de 10 de agosto, de transferencia de competencias a Canarias y Comunidad Valenciana, respectivamente.

6 Ley Orgánica 5/1083, de 1 de marzo, por la que, en aplicación del art. 144. c) de la Constitución, se incorporó la provincia de Segovia a la Comunidad autónoma de Castilla y León, constituida como tal en virtud de su Estatuto, aprobado por Ley Orgánica 4/1983, de 25 de febrero. 
1999; sin olvidar el nuevo sistema de financiación o el impulso de reforma constitucional para dar una configuración al Senado, más acorde con su naturaleza constitucional.

\section{LOS PACTOS AUTONÓMICOS DE 1981}

Uno de los acontecimientos más importantes en el proceso de conformación de nuestro Estado autonómico fue la firma de los pactos autonómicos suscritos en 31 de julio de 1981 por el Gobierno y el partido que lo sustentaba, entonces de UCD, y por el PSOE, principal partido de la oposición. En aquellos acuerdos ya se indicó que el Título VIII de la Constitución no consagra una ordenación cerrada o estática de la organización territorial del Estado, sino que constituye un amplio marco que permite la satisfacción de las voluntades de autogobierno de las distintas Comunidades Autónomas. Su desarrollo - se decía-es, por lo tanto, una prolongación natural del proceso constituyente.

Con aquellos acuerdos, se pretendió:

- diseñar las bases operativas del proceso autonómico.

- la generalización del proceso para lograr, en un plazo razonable de tiempo, una distribución homogénea del poder, reconociendo las diversas peculiaridades de las nacionalidades y regiones.

- la armonización del desarrollo institucional y legislativo autonómico para lograr una mayor claridad del ordenamiento y una reafirmación de la seguridad jurídica?.

La transcendencia de aquellos pactos Ilega hasta nuestros dias, no sólo porque fue diseñado el actual mapa autonómico, prefijando las Comunidades Autónomas que había que constituir - junto a País Vasco, Cataluña y Galicia, cuyos Estatutos ya habían sido aprobados-, sino también porque se predeterminó la vía de acceso a la autonomía, la prevista en el art. $143 \mathrm{CE}$, para todas las demás Comunidades, con excepción de Andalucía, que ya tenía celebrado el referéndum de ratificación de la iniciativa autonómica; se establecieron pautas para la aprobación por las Cortes Generales de los proyectos de Estatuto en trámite; y se pactaron una serie de cuestiones relativas a los órganos de representación y gobierno de las futuras Comunidades Autónomas,

7 Acuerdos Autonómicos 1981. Servicio de Publicaciones de la Presidencia del gobierno. Colección Informe, $\mathrm{n} .^{\circ} 36$. Madrid, octubre de 1981, págs. 10-11. 
que, de alguna u otra forma, dejaban en entredicho aquel principio dispositivo o de voluntariedad. tiones:

Así, quedaban sorprendentemente prefijadas, entre otras cues-

- que la circunscripción electoral, en las Comunidades pluriprovinciales, sería la provincia.

- que las elecciones en las Comunidades Autónomas se celebrarán el mismo día, para lo que deberían establecerse los mecanismos conducentes a tal fin.

- que los períodos de sesiones de las Asambleas de las Comunidades Autónomas - se huía del término parlamento-, serían limitados,-comprenderían cuatro meses-, determinándose aquellos entre los que debían celebrarse.

- que los miembros de las Asambleas sólo percibirán dietas, pero no consignaciones o sueldos fijos ni periódicos.

- que el Consejo de Gobierno no podría disolver la Asamblea, aunque dejaba la puerta abierta a la disolución automática para el supuesto en que no pudiera elegirse Presidente de la Comunidad en el plazo de dos meses desde la primera votación de investidura.

- que los Consejos de Gobierno se compondrían, como máximo, de diez miembros con cargos de responsabilidad ejecutiva.

Por último, se establecían una serie de previsiones relativas a las relaciones entre las Comunidades Autónomas y las Diputaciones Provinciales.

Podría considerarse que, aquellos Pactos autonómicos de 1981, a más de orillar el principio dispositivo, y por tanto, el texto constitucional, encerraban un recelo negativo hacia lo que podrían ser las futuras Comunidades Autónomas.

$Y$ evidenciaron una desconfianza hacia los futuros gobiernos autonómicos, que se quiso justificar en la necesidad de contrarrestar a una opinión pública que consideraba, entonces, que las "autonomías" iban a comportar la desintegración de España y, en todo caso, una multiplicación de cargos políticos y un despilfarro de fondos públicos.

De esta manera, con los Pactos de 1981, se implantó la generalización del régimen de autonomía a todo el territorio del Estado, pues, en los dos años siguientes, fueron aprobados todos los Estatutos de 
Autonomía, con excepción de los de Ceuta y Melilla, que no accederán a su status de ciudades autónomas hasta 1995.

Así, tras la aprobación de los 17 Estatutos, pudo hablarse de 3 grupos de Comunidades Autónomas:

- País Vasco, Cataluña, Galicia y Andalucía, que accedieron a la autonomía por la vía del art. $151 \mathrm{CE}$ - las tres primeras, además, beneficiándose de las facilidades que les reconocía la Disposición Transitoria Segunda de la CE-, obteniendo el máximo grado de autonomía inicialmente posible, dentro del marco delimitado por el art. $149 \mathrm{CE}$.

- Comunidad Valenciana y Canarias, que asumieron además de las competencias permitidas por el art. $148 \mathrm{CE}$, todas las demás constitucionalmente posibles, hasta el límite del art. $149 \mathrm{CE}$, en virtud de sendas leyes orgánicas por las que el Estado les transfirió éstas, al amparo de lo dispuesto en el art. 150.2 CE; y Navarra, con un régimen especial, derivado de su Ley de Amejoramiento del Fuero.

- Las 10 restantes Comunidades Autónomas, llamadas de régimen común, que habían de esperar, conforme a lo dispuesto en el art. 148.2 CE, un mínimo de 5 años para poder ampliar su grado de autonomía, asumiendo nuevas competencias.

\section{LAS REFORMAS ESTATUTARIAS DE 1991}

En 1991 se acometió la reforma de varios aspectos relacionados con el régimen electoral general8. La voluntad estatal de que las elecciones autonómicas se celebraran, en la mayoría de las Comunidades Autónomas, en la misma fecha, y que coincidieran con las elecciones municipales, a fin de evitar una pluralidad de procesos electorales en un corto espacio de tiempo, se tradujo en la reforma de un total de siete Estatutos de Autonomía, fruto del pacto que, con tal objetivo, habían alcanzado los dos principales partidos con representación parlamentaria, el PSOE y el PP.

La reforma no afectó a aquellas Comunidades cuyos Presidentes tenían reconocida la facultad de disolución del parlamento en sus respectivos ordenamientos jurídicos - las cuatro que accedieron a la autonomía por la vía del art. 151 de la $\mathrm{CE}-$, ni a aquéllas otras que, como

8 Ley Orgánica 8/1991, de 13 de marzo, de modificación de la Ley Orgánica $5 / 1985$, del régimen electoral general. 
La Rioja9, Aragón 10 , o Castilla-León ${ }^{11}$, cuentan con Estatutos en los que se prescribe o se permite que la celebración de las elecciones autonómicas coincida con las locales y con las de otras Comunidades Autónomas.

Así, por las Leyes Orgánicas 1 a 7 de 1991, de 13 de marzo, se modificaron los Estatutos de autonomía de Cantabria, Comunidad Valenciana, Murcia, Castilla-La Mancha, Extremadura, Asturias y Madrid. Una reforma teledirigida que responde, más que al principio de voluntariedad de las propias Comunidades afectadas, a razones de Estado, pactadas más allá de las sedes autonómicas. A partir de entonces, y hasta que se acometa una nueva reforma de los Estatutos de Autonomía, las elecciones habrían de celebrarse "el cuarto domingo de Mayo cada cuatro años, en los términos previstos en la Ley que regule el Régimen Electoral General». Consecuencia es que el mandato de los parlamentos ya no será de cuatro años, como proclaman los Estatutos, pues lo impiden los trámites pre y post electorales.

No es razonable que un Estado esté sometido, de forma casi permanente, a constantes procesos electorales en distintas partes de su territorio. Ello comporta un gasto público desmesurado, una distracción de los gobernantes en las necesarias campañas electorales, en detrimento de sus funciones de gobierno, y un posible desinterés del pueblo permanentemente llamado a las urnas. Desde esta perspectiva, la reforma de los Estatutos de 1991 fue positiva. Pero tampoco es razonable que tal solución se "diseñe" tan solo para determinadas Comunidades Autónomas, permitiendo que otras, precisamente las llamadas, en mi opinión sin rigor, "Comunidades históricas", puedan celebrar a su antojo las elecciones de sus representantes parlamentarios. Más adelante volveremos sobre esta cuestión.

9 El art. 18.4 del Estatuto de autonomía de La Rioja, aprobado por Ley Orgánica 3/1982, de 9 de junio, establece que "la convocatoria de las elecciones se realizará por el Presidente de la Comunidad Autónoma, pudiendo coincidir con las elecciones locales, y su celebración se ajustará al calendario que el Gobierno de la Nación señale, si fuere simultáneo para otras Comunidades Autónomas».

10 Disposición Adicional $4^{\mathrm{a}}$ del Estatuto de Aragón, aprobado por Ley Orgánica 8/1982, de 10 de Agosto., que dispone que "la celebración de elecciones atenderá a lo que dispongan las Cortes Generales con el fin exclusivo de coordinar el calendario de las diversas consultas electorales".

11 El artículo 11-1a de su Estatuto de autonomía, aprobado por Ley Orgánica 4/1983, de 25 de Febrero, dispone que "la convocatoria de las elecciones se realizará por el Presidente... de manera que su celebración coincida con las consultas de otras Comunidades Autónomas». 


\section{LOS PACTOS AUTONÓMICOS DE 1992}

El 28 de febrero de 1992, el Gobierno de la Nación, el partido que lo sustentaba -entonces el PSOE-, y el PP, principal partido de la oposición, suscribieron unos pactos en los que manifestaban que el desarrollo del Título VIII de la CE, que se había concebido siempre como una cuestión que afecta a la esencia misma del Estado, debía ser objeto de un consenso fundamental entre las diversas fuerzas políticas que expresan el pluralismo en las Cortes Generales.

Cumplidos los plazos mínimos previstos en la Constitución para proceder a la ampliación de las competencias de las Comunidades Autónomas que por haber accedido a la autonomía por la vía del art. 143 no pudieron asumir en sus Estatutos más competencias que las establecidas en el art. 148.1, y teniendo en cuenta la consolidación de las instituciones autonómicas y la experiencia sobre el funcionamiento del Estado autonómico, se consideraba el momento óptimo para impulsar el perfeccionamiento del modelo hacia un horizonte definitivo.

El objetivo de estos Acuerdos era la tendencia, no tanto a la igualación competencial - pues el Tribunal Constitucional en diferentes Sentencias insiste en la idea de la imposibilidad de una igualación competencial-12, sino más bien a la equiparación competencial de todas las Comunidades Autónomas ${ }^{13}$.

La ampliación de las competencias,-que se concretan en los propios Acuerdos-, se había de llevar a cabo mediante la delegación o transferencia acordada por las Cortes Generales al amparo del artículo 150.2 de la Constitución, plasmada en una Ley Orgánica en la que se incluyeran, para todas las Comunidades Autónomas afectadas, las materias objeto de la ampliación competencial pretendida para, a continuación, promover la reforma de los respectivos Estatutos de Autonomía, a fin de incorporar a aquéllos las competencias transferidas, variando, de este modo, la naturaleza de éstas.

Además, se convino por los firmantes de los Acuerdos promover la necesaria iniciativa de reforma de los Estatutos de Autonomía de Canarias y de la Comunidad Valenciana, a fin de dejar incorporadas a los mismos las competencias transferidas por las Leyes Orgánicas 11 y

12 STC 37/97.

13 A. Ruiz Huerta Carbonell, "Los Acuerdos autonómicos de 28 de febrero de 1992: ¿una alternativa constitucional adecuada?", Revista de Estudios Políticos, n. ${ }^{\circ} 81$, julio-septiembre de 1993, pág. 111. 
12 de $1982^{14}$, y a votar su aprobación en las Cortes Generales, siempre que las iniciativas de reforma respondieran estrictamente al contenido antes indicado.

En cumplimiento de lo dispuesto en aquellos Pactos, se promulgó la «Ley Orgánica 9/1992, de 23 de Diciembre, de transferencia de competencias a Comunidades Autónomas que accedieron a la autonomía por la vía del artículo 143 de la Constitución", con el doble objetivo de racionalizar el proceso, posibilitando un funcionamiento ordenado y estable del Estado autonómico y de dar satisfacción a las aspiraciones de las Comunidades autónomas del art. 143, de asumir las nuevas competencias mediante la reforma de sus Estatutos, aspiraciones que habían sido muy especialmente reivindicadas, desde hacía ya varios años, por Aragón.

Y cumpliendo las previsiones de aquellos Acuerdos de 1992, se promulgaron en Marzo de 1994, un total de doce Leyes Orgánicas que modificaron diversos preceptos de los Estatutos de Autonomía de Asturias, Cantabria, la Rioja, Murcia, Aragón, Castilla-La Mancha, Extremadura, Baleares, Madrid y Castilla-León15; añadieron una Disposición Adicional al Estatuto de Autonomía de la Comunidad Valenciana16; y fue derogada la LOTRAVA 17.

Sin embargo, no se reformó el Estatuto de Autonomía de Canarias ni se derogó la Ley Orgánica 11/1982, por la que transfirieron a di-

14 Leyes Orgánicas promulgadas simultáneamente a las de aprobación de sus Estatutos de autonomía, en virtud de las cuales fueron transferidas a Canarias y a la Comunidad Valenciana más competencias que las enumeradas en el artículo 148.1 de la Constitución, pese a su acceso a la autonomía por la vía del artículo $143 \mathrm{CE}$.

15 Leyes Orgánicas 1 a 4, de 24 de marzo de 1994, de reforma de los Estatutos de autonomía de Asturias, Cantabria, La Rioja y Murcia; y 6 a 11, de la misma fecha, de reforma de los de Aragón, Castilla-La Mancha, Extremadura, Baleares, Madrid y Castilla y León.

16 Ley Orgánica 5/1994, de 24 de marzo. La nueva Disposición Adicional Tercera prescribe que «Todas las competencias atribuidas por el presente Estatuto quedan atribuidas a él plenamente, asumiéndose con carácter estatutario por la Generalitat Valenciana".

17 Ley Orgánica 12/1994, de 24 de marzo, por la que se derogó la Ley Orgánica 12/1982, de 10 de agosto, de transferencias, a la Comunidad Valenciana, de competencias de titularidad estatal. A partir de ese momento, las competencias enumeradas en el Estatuto valenciano, que excedían de las previstas en el artículo 148.1 de la Constitución, y que la Generalitat Valenciana ostentaba por título de transferencia estatal, pasaron a tener naturaleza estatutaria, dejando de ser susceptibles de control extraordinario por parte del Estado. 
cha Comunidad competencias de titularidad estatal, toda vez que esta Comunidad Autónoma se mantuvo al margen de estas reformas al ser minoritarios el PSOE y el PP en los momentos de su gestación y contar, con mayoria absoluta, las fuerzas luego integradas en Coalición Canaria. Esta circunstancia, como advierte Gumersindo Trujillo ${ }^{18}$, condicionó en un primer momento el proceso reformador del Estatuto canario, iniciado en 1991, pero finalizado en 1996, al promulgarse la Ley Orgánica 4/1996, de 30 de diciembre, a la que más adelante me referiré.

Hay que mencionar, en relación con Galicia, la promulgación de la Ley Orgánica 16/1995, de transferencia de competencias, a fin de completar las establecidas en su Estatuto, y lograr una equiparación con las restantes Comunidades Autónomas ${ }^{19}$.

No es momento ni lugar adecuados para valorar la forma en que, inicialmente, como consecuencia de aquellos Acuerdos de 1992, se amplió el ámbito competencial de las Comunidades de vía lenta y de Galicia ${ }^{20}$. La previa transferencia de las competencias a través de la Ley Orgánica promulgada al amparo del art. 150.2 de la Constitución trató de homogeneizar el techo competencial de las Comunidades Autónomas y de vincular la ulterior reforma de los Estatutos de las Comunidades afectadas, evitando, de este modo, demandas dispares.

18 idntegración constitucional de los hechos diferenciales y preservación de la cohesión básica del Estado autonómico", en "Asimetría y cohesión en el Estado autonómico". M.A.P., Colección Informes y Documentos, Serie Administraciones Territoriales. Madrid, 1997, pág. 16.

19 La ampliación de competencias a Galicia se desarrolla por medio de la citada Ley, utilizando la vía prevista en el artículo 150.2 de la Constitución. Incluye aquellos títulos competenciales que, asumidos por las restantes Comunidades Autónomas, no se recogían en el Estatuto de Autonomía -aprobado por Ley Orgánica 1/1981, de 6 de abril-, y la equiparación, en cuanto al contenido de las competencias, en relación con aquéllas que, en el Estatuto, aparecen asumidas en niveles competenciales inferiores a los asumidos por las restantes Comunidades Autónomas.

Asi, por ejemplo, se le transfiere la competencia exclusiva en materia de espectáculos, o cooperativas y mutuas no integradas en el sistema de Seguridad Social.

20 Una crítica a la vía del art. 150. 2 CE como mecanismo de ampliación competencial puede verse en la op. cit. de A. Ruiz-Huerta CarbonelL, pág. 118.

Sobre el significado de dicho artículo, vid. M. Bassols Coma y J. M. Serrano AlBerCA, «El artículo 149 de la CE en relación con el artículo 150.2: análisis de la delegación en materia de las competencias exclusivas estatales", Revista de Administración Pública, n. ${ }^{\circ}$ 97, pág. 31 y ss.; y S. MuÑoz MaCHADO, Derecho Público de las Comunidades autónomas, E. Civitas. Madrid, 1982, pág. 175 y ss. 
Si bien pudiera pensarse que esta forma de proceder resultó contraria al principio dispositivo que la Constitución consagra,-habida cuenta el derecho de reforma concebido como originalmente libre por la Constitución y garantizado por la misma-, no lo es menos que la valoración de los Pactos de 1992 ha de ser positiva al haber posibilitado un sistema más racional y satisfecho, en definitiva, y en general, las legítimas aspiraciones de las Comunidades con autonomía menos plena que, transcurridos ya una decena de años desde la vigencia de sus Estatutos, pretendían un mayor grado de autogobierno21.

Como ha recordado Muñoz Machado22, el Informe de la Comisión de expertos de 19 de Mayo de 1981, que sirvió de base para los Pactos autonómicos de aquel año, hizo notar que la disparidad competencial a que podía abocar la diversidad de Estatutos de Autonomía, conducía a un sistema difícilmente operativo, destacando la posibilidad de que el Estado, como totalidad organizativa, tuviera que ajustarse simultáneamente a dos patrones distintos, ordenarse sobre la base de dos modelos opuestos, producir normas de estructura y alcances diferentes para cada parte del territorio, desarrollar políticas distintas en cada espacio concreto y funcionar, en fin, con arreglo a dos mentalidades.

Si con los Pactos autonómicos de 1981 se pretendió la generalización del régimen de autonomía para todo el territorio del Estado, con los de 1992, se intentó la homogeneización competencial, acercando las Comunidades de autonomía menos plena a la homologación con las que, $a b$ initio, contaron con mayores competencias.Dos etapas de singular importancia en la configuración de nuestro Estado autonómico ${ }^{23}$.

21 Un juicio de valor positivo lo realiza S. MuÑoz MACHADo, en "Los pactos autonómicos de 1992: la ampliación de competencias y la reforma de los Estatutos", Revista de Administración Pública, n. ${ }^{\circ} 128$, pág. 90 y ss., aunque formula algunas críticas a la utilización previa de una transferencia generalizada por medio de la Ley Orgánica dictada al amparo del art. 150.2 de la CE.

22 ¿Los pactos autonómicos...», cit., pág. 86.

23 Adolfo Hernández Lafuente y M.. Ángeles González García consideran que, no obstante, el resultado de los Pactos autonómicos de 1992 ofrece diversas manifestaciones de heterogeneidad competencial entre las Comunidades autónomas, pues observan, por ejemplo, que hay competencias reconocidas a las comunidades del 143 que ni siquiera tienen reconocidas todas las del 151, como verbigracia, la ejecución de la legislación penitenciaria, el transporte fluvial o el nombramiento de Corredores de Comercio y Agentes de Cambio y Bolsa; o que existen títulos generales en los Acuerdos, en los que no se produce la equiparación con las Comunidades del 151, como seguridad social, ordenación del crédito, banca y seguros.Vid. en "Los Acuerdos autonómicos de 28 de Febrero de 1992: negociación, contenido y desarrollo», en Documentación Administrativa, n. ${ }^{\circ} 232-233$, pág. 136 y ss. 
Aunque hay quien se lamenta de que estas generalización y homologación truncaran la posibilidad de instaurar un sistema autonómico diferencial, a medida de realidades muy diferentes como en España hay ${ }^{24}$, no encontramos razones convincentes, ni políticas, ni jurídicas, que justifiquen un modelo desigual, de autonomía reservada a muy pocas comunidades, o basado en una inicial diversidad dominante. Es esta una cuestión que, pese a parecer que ha quedado superada en la evolución de nuestro Estado autonómico, continúa constituyendo fuente de conflictos $y$ tensiones que provienen, fundamentalmente, de los nacionalismos catalán y vasco.

Por último, cabe recordar que los Acuerdos autonómicos de 1992, además de la referida homogeneización competencial, contenían una serie de pautas para desarrollar el principio de cooperación, como consustancial al buen funcionamiento del Estado autonómico, fomentando un sistema de relaciones asentado sobre una actitud de recíproca lealtad constitucional y estatutaria.

Consecuencia fue el reconocimiento institucional de las Conferencias Sectoriales, ya previstas en la Ley 12/1983, de 14 de octubre, del Proceso autonómico25, como el medio habitual y normal para articular las actuaciones de las diversas Administraciones Públicas, debiendo constituirse en órganos efectivos de trabajo con contenido y vida propia, para lo que se consideraba preciso dotarlas de estructura, principios y mecanismos de funcionamiento que garanticen la participación, la adopción de acuerdos y su cumplimiento. $Y$ de igual mane-

Garcia Roca ha indicado al respecto, que la opción homogeneizadora de las competencias resulta, en la práctica, casi una misión imposible o, más matizadamente, un rompecabezas al que siempre le falta alguna pieza y nunca se llega a ultimar por mucho que se avance en su composición.Vid. en «España asimétrica (Descentralización territorial y asimetrías autonómicas: una especulación teórica)", en Asimetría y cohesión en el Estado autonómico, cit., pág. 71.

24 M. Herrero de MiÑon, «La posible diversidad de los modelos autonómicos en la transición, en la Constitución española de 1978 y en los Estatutos de autonomía", en Uniformidad o diversidad de las Comunidadès autónomas, Generalitat de Cataluña, Institut d'Estudis Autonomics, Barcelona 1995, pág. 15.

25 La citada Ley mantiene los preceptos de la Ley Orgánica de Armonización del Proceso autonómico (LOAPA) -a la cual sustituye-, que no fueron declarados inconstitucionales por la STC 76/1983, de 5 de Agosto. Su art. $4 .{ }^{\circ}-1$ establece que, a fin de asegurar en todo momento la necesaria coherencia en la actuación de los poderes públicos y la imprescindible coordinación, se reunirán de forma regular o periódica, al menos dos veces al año, Conferencias Sectoriales de los Consejeros de las distintas Comunidades autónomas y del Ministro o Ministros del ramo, para intercambiar puntos de vista y examinar en común problemas de cada sector $y$ las acciones proyectadas para afrontarlos y resolverlos. 
ra, se consideró que había que impulsar las Comisiones Bilaterales de Cooperación, como instrumento efectivo para realizar el intercambio continuado de informaciones, negociaciones y acuerdos para dar respuesta a las necesidades derivadas de las peculiaridades geográficas, culturales, lingüísticas o del contenido estatutario de cada Comunidad autónoma.

Tanto a las Conferencias Sectoriales como a las Comisiones Bilaterales de Cooperación se refiere el art. 5 de la Ley 30/92, de 26 de noviembre, de Régimen Jurídico de las Administraciones Públicas y del Procedimiento Administrativo Común, cuya redacción y contenido ha mejorado ostensiblemente la Ley $4 / 99$, de 14 de enero, $y$ de hecho se hallan constituidas y en funcionamiento Comisiones Bilaterales de Cooperación de todas las Comunidades Autónomas, excepto Madrid y Comunidad Valenciana.

\section{EL PERFECCIONAMIENTO DEL SISTEMA DE AUTOGOBIERNO: REFORMAS ESTATUTARIAS 1996-1999}

Las reformas de los Estatutos de Autonomía de las Comunidades del 143, aprobadas en Marzo de 1994, tuvieron como objeto, como ha quedado expuesto, ampliar las competencias de aquéllas, habida cuenta que las tenían limitadas a las establecidas en el art. 148.1 de la Constitución, y que habían transcurrido más de cinco años desde la vigencia de sus Estatutos. En los Acuerdos Autonómicos de febrero de 1992 se limitaba a aquella ampliación la reforma de los Estatutos, sin posibilidad de que, aprovechando el proceso de reforma, se canalizaran otras pretensiones.

Era una aspiración de estas Comunidades Autónomas completar, mejorar $y$, en fin, perfeccionar, su sistema de autogobierno, introduciendo, para ello, retoques en sus normas institucionales básicas, reconociendo a sus instituciones determinadas facultades de las que carecían, o suprimiendo límites de difícil justificación.

Como se ha visto, los Pactos Autonómicos de Julio de 1981 encerraban cierta desconfianza o recelo en torno a la estructura y funcionamiento de las futuras Comunidades Autónomas, por lo que trataron de configurarlas en base a un patrón que, en cierto modo, limitaba su plena capacidad de autoorganización. Este dato, unido a la lógica comparación con las Comunidades del 151, propició el inicio de un proceso de reformas, que comenzó en diciembre de 1996 con las de los Es- 
tatutos de Canarias y de Aragón, hasta llegar a la más reciente, en mayo de 1999, del de Extremadura.

Un total de once Estatutos de Autonomía se han visto reformados a lo largo de estos últimos tres años 26 a los que habrá que sumar, previsiblemente, en un futuro inmediato, los de la Comunidad Valenciana ${ }^{27}$ y Navarra. Y se ha ampliado el ámbito competencial de Cataluña, al haberle transferido el Estado competencias ejecutivas en materia de tráfico y circulación de vehículos a motor 28 .

¿Cuál es el objetivo y el contenido de estas últimas reformas?

a) En primer lugar, incrementar y concretar las materias sobre las que las Comunidades Autónomas afectadas tienen alguna competencia, llegando a la practica equiparación con las contenidas en los Estatutos de las del 151.

Hay que advertir que la pretensión de un estudio comparativo que concluya con la más absoluta equiparación competencial es tarea harto compleja cuando no imposible, habida cuenta que un título com-

26 Las Leyes Orgánicas por las que aprobaron las reformas de los Estatutos de autonomía, son las siguientes:

- L.O. 4/1996, de 30 de diciembre, Canarias.

- L.O. 5/1996, de 30 de diciembre, Aragón.

- L.O. 3/1997, de 3 de julio, Castilla-La Mancha.

- L.O. 1/1998, de 15 de junio, Murcia.

- L.O. 5/1998, de 7 de julio, Madrid.

- L.O. 11/1998, de 30 de diciembre, Cantabria.

- L.O. 1/1999, de 5 de enero, Principado de Asturias.

- L.O. 2/1999, de 7 de enero, La Rioja.

- L.O. 3/1999, de 8 de enero, Islas Baleares.

- L.O. 4/1999, de 8 de enero, Castilla y León.

- L.O. 11/1999, de 6 de mayo, Extremadura.

27 En la Comunidad Valenciana, durante la IV Legislatura, se constituyó en las Cortes Valencianas una Comisión especial para el estudio de la reforma del Estatuto de autonomía, que no pudo concluir sus trabajos, no iniciándose, por tanto, el proceso de reforma. Los tres partidos políticos que han obtenido representación parlamentaria en las pasadas elecciones del día 13 de junio -PP, PSOE y EU-, contemplaban en sus programas electorales la necesidad de reformar el Estatuto, siendo, para todos ellos, prioritario iniciar los trámites conducentes a tal fin, por lo que es de esperar que en esta $V$ Legislatura recién estrenada, se apruebe la proposición de Ley Orgánica de reforma para su ulterior remisión al Congreso de los Diputados.

28 Ley Orgánica 6/1997, de 15 de diciembre. En su Exposición de motivos, se justifica la transferencia en la existencia en Cataluña de la Policia de la Generalitat-Mossos d'Esquadra, con competencia en materia de seguridad ciudadana, "que la tradición administrativa vincula a la de tráfico". 
petencial concreto puede encerrar en su seno la posibilidad de otros anejos a aquél por razones de conexión temática o por lógica jurídica. Por ejemplo, cuando se dice que una Comunidad Autónoma tiene competencia exclusiva en relación a la organización de sus Instituciones de autogobierno, parece que se está diciendo lo mismo que si se indica que dicha competencia lo es sobre organización, régimen y funcionamiento de aquéllas.

Si a ello unimos el hecho de que determinadas Comunidades Autónomas tienen asumidas competencias derivadas de razones geográficas,-por ejemplo, en relación con el litoral, las denominaciones de origen o la insularidad-; lingüísticas, por poseer lengua propia cooficial con el castellano; o culturales o históricas, como la conservación, modificación y desarrollo del derecho civil propio, es fácil que lleguemos a la conclusión de que la igualación competencial absoluta, no sólo es imposible, sino contraria a un orden lógico de distribución competencial.

Pero sí que puede afirmarse que hoy, tras las reformas estatutarias de los años 1996-99, existe una práctica equiparación entre las competencias de unas y otras Comunidades Autónomas, incluidas las del 151, con lo que se ha conseguido, en términos generales, la homologación que, al menos tímidamente, pretendían los Acuerdos autónomicos de 1992 y la aspiración de las Comunidades menos autónomas.

De ahí que renunciemos al trabajo ímprobo del posible estudio comparativo antes apuntado.

b) En segundo lugar, se ha dado reconocimiento estatal, mediante la aprobación de las correspondientes Leyes Orgánicas, a determinadas aspiraciones de algunas Comunidades Autónomas respecto a su consideración como nacionalidad histórica.

Así, los Estatutos de Canarias y Aragón se refieren a dichas Comunidades como nacionalidades - término anteriormente reservado para las del 151 o para la Comunidad Valenciana-, mientras que los Estatutos de Cantabria y Asturias se refieren a éstas como "comunidad histórica» 29.

29 Cuando redacto estas líneas - 11 de julio de 1999-, la prensa publica la noticia de las negociaciones que, en las Islas Baleares, desarrollan las fuerzas políticas con representación parlamentaria en orden a la formación del nuevo gobierno autonómico, al no contar ninguna de aquéllas con mayoría absoluta. Una de las ofertas del PP a UM, a fin de obtener sus votos en la investidura de su candidato a Presidente, consiste en la consideración y reconocimiento de las Islas, supongo que 
En otros casos, se han concretado los símbolos identificativos, como en los Estatutos de Madrid y La Rioja; se ha garantizado la protección de las lenguas y modalidades lingüísticas, en Aragón y Asturias, declarándose en el de Castilla y León que la lengua castellana es un valor esencial para la identidad de la Comunidad; o se ha incluido en el texto del Estatuto la mención a instituciones de autogobierno ya constituidas o cuya creación se pretende. Tal ocurre respecto de los Consejos Consultivos autonómicos, en Baleares, Asturias o Castilla-La Mancha, dándole una nueva configuración en Canarias; o en relación con las figuras afines al Defensor del Pueblo (Cantabria), o al Tribunal de Cuentas (Asturias).

Se reconoce la posibilidad de la delegación legislativa en el Gobierno, y su forma, en los Estatutos de Asturias y Extremadura.

Y por último, en el caso de Castilla y León, se hace expresa mención a la provincia de Segovia como parte integrante del territorio de la Comunidad 30 , y en el de La Rioja, se establece la capitalidad de la Comunidad en Logroño, antes sólo sede de las instituciones de gobierno.

c) Pero además, con estas reformas se han suprimido aquellas limitaciones provenientes de los Pactos Autonómicos de 1981, que afectaban a la configuración y funcionamiento de las instituciones de gobierno autonómicas.

Así, se suprime en los Estatutos la referencia a que los respectivos Consejos de Gobierno no podrían contar con más de diez miembros con funciones ejecutivas, o que los períodos de sesiones de los Parlamentos no podían durar más de dos meses; reforma que parece lógica, teniendo en cuenta el gran número de competencias que las Comunidades Autónomas tienen asumidas, lo que se traduce en una vida parlamentaria que exige mayor actividad, y en unos ejecutivos cuya estructura interna no tiene por qué estar predeterminada. De esta manera queda a la prudencia de los responsables políticos, en cada momento y lugar, la determinación del número de personas que han de conformar los gobiernos.

mediante la reforma del Estatuto - jotra más!--, como "nacionalidad histórica", a más de 100.000 millones de pesetas en inversiones para la Comunidad.Vid. en El Mundo, págs. 8-9.

30 Recuérdese que Segovia fue incorporada a la Comunidad de Castilla y León, por Ley Orgánica $5 / 1983$, de 1 de marzo, promulgada en aplicación de lo dispuesto en el art. 144.c) de la Constitución. 
d) Pero, sin duda alguna, la reforma más relevante es la que afecta a la facultad de disolución de los parlamentos autonómicos por parte de los Presidentes de los ejecutivos.

Como es sabido, una de las notas que caracteriza al sistema parlamentario de gobierno es la facultad de disolución del parlamento por parte del ejecutivo ${ }^{31}$. Sin embargo, los Estatutos de Autonomía no preveían el acortamiento del mandato de los parlamentos, establecido en cuatro años.

Promulgados sus Estatutos sin previsión al respecto, las Comunidades de País Vasco, Cataluña, Galicia y Andalucía aprobaron leyes en las que establecieron la disolución automática del parlamento al estilo de la prevista en el art. 99.5 de la Constitución, y reconocieron a los Presidentes de sus Gobiernos la facultad de disolverlo anticipadamente, utilizando, de esta manera, un procedimiento dudosamente constitucional ${ }^{32}$. Efectivamente, la restricción del mandato parlamentario en la forma establecida en los Estatutos no puede menos que establecerse en el propio Estatuto, pues de otro modo se contrarían las propias prescripciones estatutarias ${ }^{33}$. Además, la vía legislativa no es la idónea para conferir facultades no previstas en el Estatuto, y que no cabe inferir de la genérica competencia en relación con la autoorganzación de las instituciones de gobierno.

El ejemplo no fue seguido por otras Comunidades Autónomas, aunque algunos Estatutos sí preveían la disolución automática si transcurridos dos meses desde la primera votación de investidura, la Asamblea no había logrado elegir Presidente.

Las reformas estatutarias de 1996-1999 han reconocido, en la mayor parte de los Estatutos reformados, la facultad presidencial de di-

31 Vid. K. Loewenstein, Teoría de la Constitución, E. Ariel. Barcelona, 1986, pág. 107 y ss. Es célebre su frase «El derecho de disolución del Parlamento y el voto de confianza están juntos como el pistón y el cilindro en una máquina". Vid., asimismo, A. BAR CENDÓN, La disolución de las Cámaras legislativas en el ordenamiento constitucional español, Congreso de los Diputados, Madrid, 1989.

32 Ley 7/1981, de 30 de junio, del Gobierno del País Vasco; Ley 8/1985, de 24 de mayo, de modificación de la Ley 3/1982, de 25 de marzo, del Parlamento, del Presidente y del Consejo Ejecutivo de la Generalidad de Cataluña; Ley 11/1988, de 20 de octubre, de la Junta de Galicia y de su Presidente; y Leyes $1 / 1990$, de 30 de enero y 6/1994, de 18 de mayo, por las que se modifica la Ley 6/1983, de 21 de julio, del Gobierno y la Administración de la Comunidad autónoma de Andalucía.

33 Vid. A. Bar Cendón, op. cit., pág. 292. 
solver anticipadamente el parlamento, bajo su exclusiva responsabilidad y previa deliberación de su Consejo de Gobierno.

Pero es una disolución que se configura con ciertos límites en cuanto a su ejercicio. Se trata de lo que Arnaldo denomina «condiciones de ejercicio ${ }^{34}$ y Loewenstein, "medidas de seguridad" que tienen por objeto que el control interorgánico más poderoso pueda llegar a convertirse en instrumento destructor del propio sistema35.

Fue la reforma del Estatuto de Autonomía de Aragón, de 1996, la que marcó la pauta que habrian de seguir las posteriores de Madrid, Cantabria, Asturias, Castilla-La Mancha, Murcia, La Rioja, Castilla y León y Extremadura.

En aquel Estatuto se somete la disolución discrecional a las siguientes condiciones:

1. No puede decretarse durante el primer periodo de sesiones de la Legislatura.

2. Tampoco, cuando reste menos de un año para su terminación.

3. Ni cuando se encuentre en trámite una moción de censura.

4. Ni antes de que transcurra un año desde la última disolución discrecional.

5. Ni cuando se halle convocado un proceso electoral estatal.

En todo caso, la nueva cámara tendrá un mandato limitado por el término natural de la Legislatura originaria.

Ello no obstante, algunos Estatutos continúan previendo que las elecciones autonómicas se celebren el cuarto domingo del mes de mayo cada cuatro años, en los términos previstos en la Ley de Régimen Electoral General (Asturias), o que se atenderá a lo que dispongan las Cortes Generales con el fin exclusivo de coordinar el calendario de las diversas consultas electorales (Castilla-La Mancha).

La conclusión que cabe extraer de todo lo expuesto es que mediante el reconocimiento del derecho de disolución, aún con los condicionantes reseñados, se ha perfeccionado el sistema de autogobierno de las Comunidades Autónomas, aunque queda sin respuesta convin-

34 E. Arnaldo Alcublela, "La disolución del Parlamento y el Parlamento indisolublen. Cortes, Anuario de Derecho Parlamentario, n. ${ }^{\circ}$ 6, Valencia, 1998, pág.104.

35 K. Loewenstein, op. cit., pág. 282. 
cente la pregunta de por qué esos condicionantes de ejercicio de la facultad de disolución quedan limitados sólo a algunas Comunidades, mientras que otras, las del 151, pueden continuar celebrando sus elecciones independientemente de la fecha en que tengan lugar las de las demás.

\section{EL ESTADO AUTONÓMICO: PERSPECTIVAS DE FUTURO}

Y llegados a este punto cabe que nos preguntemos: ¿hemos de considerar cerrado el modelo territorial de Estado? ¿Hacia dónde camina nuestro Estado autonómico?

De lo anteriormente expuesto se puede concluir que la constitución del Estado autonómico, no estando predeterminada en la Constitución, ha sido fruto de un conjunto de tensiones, de presiones y de acuerdos que han dependido de la correlación de fuerzas y de las circunstancias políticas que en cada momento han concurrido.

Cuando se plantea el problema de cerrar, de limitar nuestro modelo autonómico, no podemos olvidar, como recuerda Alvarez Con$\mathrm{de}^{36}$, que la propia expresión - autonómico- encierra una idea dinámica, de proceso, que, a la postre, significa que nuestro modelo de Estado no tiene por qué tener la misma naturaleza y significación en todas sus etapas de configuración.

Ello no obstante es evidente que el modelo, inicialmente indefinido, ha ido paulatinamente cerrándose o delimitándose, y que en ese proceso de configuración han intervenido una pluralidad de factores que han ido apareciendo a lo largo de estos años y a los que pueden unirse, en un futuro, otros, que propicien nuevas etapas que contribuyan a ir perfilando nuestro modelo de descentralización política.

Piénsese que la propia reforma de la Constitución, y de los Estatutos, las posibilidades que ofrece el art. 150.2 de la CE, la revisión de las fórmulas de financiación y la existencia de una jurisprudencia constitucional que va delimitando progresivamente lo que es básico, lo que

36 E. Álvarez Conde, “Homogeneidad y asimetría en el modelo autonómico español", en Asimetría y cohesión en el Estado autonómico, cit. pág. 80 . El autor considera que resulta imposible, e incluso de dudosa constitucionalidad, intentar cerrar de forma definitiva nuestro modelo de Estado. 
debe ser supletorio, o el concepto mismo de autonomía, impiden que podamos proclamar el cierre del modelo.

Pero lo que es evidente es que hemos alcanzado una cultura autonómica hoy irreversible, y llegado a un punto de estabilidad, sólo perturbado fundamentalmente, por las reivindicaciones de los nacionalistas vascos y catalanes, y en menor medida, gallegos - surgidas especialmente tras la equiparación competencial nacida de los Pactos de 1992-, que persiguen que sus Comunidades sean tan diferentes como lo fueron al principio del proceso.

En este sentido hay que destacar el debate surgido en 1998 sobre el caracter plurinacional del Estado, propiciado por la reunión conjunta del PNV, CiU y BNG, que desembocó en las Declaraciones de Barcelona, Gasteiz y Santiago de Compostela37, con las que se pretende, por los citados partidos nacionalistas, abrir nuevas líneas de reflexión y propuesta sobre el modelo de Estado, tendentes al reconocimiento jurídico-político de su carácter plurinacional, con una estructura competencial que haga efectivo tal reconocimiento.

Además, se postula un cambio de los criterios interpretativos uniformistas y poco autonomistas utilizados por el legislador estatal y corroborados, en líneas generales, por el Tribunal Constitucional que han supuesto, en opinión de los nacionalistas vascos, catalanes y gallegos, la negación de competencias exclusivas de las Comunidades Autónomas y la extensión abusiva de la legislación básica del Estado. De ahí que postulen «una nueva composición del Tribunal Constitucional, que refleje adecuadamente la pluralidad de poderes que concurren en el mismo para dirimir sus conflictos, arbitrando mecanismos que permitan que la designación de Magistrados... responda a la realidad plurinacional del Estado»38.

Estas propuestas fueron contestadas, mediante la Declaración de Mérida ${ }^{39}$ suscrita por los Presidentes de las Comunidades Autónomas de Andalucía, Extremadura y Castilla-La Mancha, en la que tras lamentarse de la existencia de posiciones nacionalistas que cuestionan la cohesión garantizada en la Constitución y niegan la soberanía de los es-

37 Las Declaraciones de Barcelona, de 16-7-98; de Gasteiz, de 16-9-98, y de Santiago de Compostela, de 31-10-98, pueden consultarse en el «Informe sobre Comunidades autónomas 1998", Instituto de Derecho Público, pág. 44 y ss.

38 Cfr. Declaración de Santiago de Compostela, cit.

39 Declaración de Mérida, de 6-10-98. En "Informe Comunidades Autónomas 1998", cit. pág. 50 . 
pañoles en su conjunto -en un momento en que ha de considerarse superado el nacionalismo español de carácter excluyente-, concluyen afirmando que no existe un derecho natural, ni previo ni posterior a la Constitución, que puede ser invocado para justificar privilegios entre los territorios o desigualdad entre los españoles. En este sentido, afirman, todas las Comunidades Autónomas tienen el derecho a los niveles de autogobierno y competencias a que aspiran dentro de lo que la Constitución admite.

Desde luego la Constitución no ampara un Estado autonómico desigual. Más allá de las diferencias de derecho - y a las que más adelante me referiré-, no encuentro en nuestro Texto Fundamental razones que avalen la diferencia permanente entre unas $y$ otras Comunidades Autónomas.

Y más aún: considero que cualquier intento en sentido contrario deviene inconstitucional.

Lo que ocurre es que, como ha destacado Carreras 40 , los partidos nacionalistas vascos y catalanes, notoriamente el PNV y CiU, necesitan, por su propia naturaleza, que el modelo estructural esté permanentemente abierto ya que es consustancial a su ideología política el aumento de competencias. $Y$ añado yo: un aumento de competencias no generalizado, pues de otro modo, la consecución de lo pretendido les genera insatisfacción.

No hace muchos años tuve oportunidad de cenar con Juan María Atutxa, entonces Consejero de Interior del Gobierno Vasco, hoy Presidente del Parlamento de aquella Comunidad. Uno de los líderes más destacados del PNV. Durante la grata conversación que mantuvimos le pregunté: ¿hasta dónde queréis llegar los vascos? ¿Cuál es vuestra meta en el Estado autonómico? Su respuesta fue tan elocuente como reveladora: Yo no puedo hipotecar el futuro de mis nietos, me dijo. No puedo responder a tu pregunta.

Si es evidente, como he indicado, que proclamar que nuestro modelo de Estado está perfectamente delimitado y cerrado presenta más inconvenientes que ventajas, no lo es menos que, en todo caso, se debe trabajar para procurar que el modelo sea estable y no sometido a presiones que encierran más que un proyecto común, un egoísmo partidista.

40 F. de Carreras Serra, "El sistema autonómico español: ¿Existe un modelo de Estado?", en Asimetria y cohesión..., cit. pág. 103. 
Considero que, para ello, es preciso abordar cuatro cuestiones de capital importancia:

1. En primer lugar, la reforma del Senado ${ }^{41}$, para lo que estimo necesaria la de la Constitución. Una nueva configuración acorde con lo que debe ser la Cámara alta en un Estado autonómico, pasa por dotarla de una distinta composición y funciones ${ }^{42}$.

Aun consciente de los riesgos que comporta iniciar un proceso de reforma constitucional, no veo otra vía posible si lo que se pretende es algo más que parchear para aparcar un problema, sin resolverlo.

La literatura jurídico-constitucional es abundante al respecto ${ }^{43} y$ no voy a extenderme más sobre esta cuestión que, por lo demás, daría para una conferencia específica sobre el tema, y que escapa al de mi intervención.

2. En segundo lugar, delimitar definitivamente el modelo de financiación autonómica: no tiene sentido estar constantemente revisándolo.

Téngase en cuenta que si alguna materia hay que afecte directamente a la capacidad de autogobierno de las Comunidades Autónomas, de ejercer sus competencias y de elaborar sus propias políticas es, sin duda, la relativa a la financiación.

Actualmente está vigente el Plan quinquenal 1997-2001 aprobado a propuesta del Gobierno, por el Consejo de Política Fiscal y Financiera de las Comunidades Autónomas en Septiembre de 1996, uno de cuyos principios inspiradores es la asunción por aquéllas, de un importante nivel de corresponsabilidad fiscal efectiva que se materializa mediante la cesión de tributos del Estado.

41 Al decir de Martínez Sospedra, tema tan viejo como el Senado Constitucional mismo.

42 Para Leguina, el Senado es la pieza más defectuosa de nuestra arquitectura constitucional. "La más defectuosa y quizás también la menos útil. Su composición y atribuciones colocan, en efecto, a esta segunda Cámara legislativa en una posición excéntrica y escasamente funcional dentro del conjunto de poderes constitucionales que integran el Ilamado Estado de las autonomías". Vid. J. Leguina VILLA, "La reforma del Senado y los hechos diferenciales», Revista de Administración Pública, n. ${ }^{\circ} 143$, mayo-agosto de 1997, pág. 7.

43 Vid., por todos, F. VISIEdo MAZón, La reforma del Senado: Territorialización del Senado. Comisión General de Comunidades Autónomas, Departamento de Publicaciones del Senado, Madrid, 1997; en sus páginas 169 y siguientes recoge las distintas alternativas de reforma de la Cámara Alta. 
Este principio de corresponsabilidad fiscal obligó a reformar el régimen general de la cesión de tributos del Estado, modificándose, por Ley Orgánica 3/96, de 27 de diciembre, la LOFCA - Ley Orgánica 8/1980, de 22 de diciembre, de Financiación de las Comunidades Autónomas-, y a promulgar la Ley 14/1996, de 30 de diciembre, de cesión de tributos a las Comunidades Autónomas y de medidas fiscales complementarias, lo que comportó las subsiguientes leyes modificativas de los artículos o disposiciones correspondientes de los Estatutos de Autonomía que relacionan los tributos objeto de cesión 44 y la atribución a las Comunidades Autónomas de la facultad de dictar para sí mismas normas legislativas, en los casos $y$ condiciones previstos en la Ley de cesión de tributos.

Hay que indicar que el nuevo modelo se aplica sólo a aquellas Comunidades Autónomas que lo han asumido. Las que no lo han hecho (Andalucía, Castilla La Mancha y Extremadura) se siguen rigiendo por el aprobado en 1992 para el quinquenio anterior, lo que significa que no todas las Comunidades Autónomas de régimen común tienen el mismo modelo de financiación.

Hace escasos dias se difundía la noticia de que el Gobierno pretendía revisar el modelo de financiación y también su calendario, a fin de ceder los impuestos especiales a las Comunidades Autónomas 45. Son varias las propuestas que en los últimos meses se han venido formulando por distintos responsables políticos que, en todo caso, deben desembocar en un consenso entre las principales fuerzas políticas a fin de lograr un sistema estable, habida cuenta el alto grado de descentralización política conseguido.

3. En tercer lugar, considero que hay que fomentar y profundizar en las técnicas de cooperación como elemento esencial del sistema autonómico 46 , aplicando las propias del llamado federalismo cooperativo que trata de superar la técnica de la separación formal y absoluta de competencias, propia del federalismo dual, evitando centrar su situación en la división constitucional de la autoridad entre el Gobierno

44 Leyes 25 a 36 de 1997, de 4 de agosto.

Curiosamente los propios Estatutos disponen que la modificación de los artículos que relacionan los impuestos cedidos no supone modificación del Estatuto, lo que resulta dificil de entender.

45 Vid. en El País de 30-6-99, pág. 11.

46 Sobre la necesaria cooperación y coordinación entre el Estado y las Comunidades Autónomas. Vid. A. Torres del Moral, Principios de Derecho Constitucional español, Universidad Complitense de Madrid, 1998, pág. 760 y ss. 
Central y el de los Estados, y resaltando la interdependencia y mutua influencia que cada nivel de gobierno es capaz de ejercer sobre el otro47.

$Y$ ese federalismo cooperativo, o autonomismo cooperativo, como señala Corcuera ${ }^{48}$, debe manifestarse tanto verticalmente, entre el Estado y las Comunidades Autónomas, como horizontalmente, entre las Comunidades Autónomas entre sí.

Es verdad que, al menos formalmente, se han producido avances significativos en este punto, que fue objeto de adecuado tratamiento en los Acuerdos Autonómicos de 1992, a los que antes me he referido, y tuvo su reflejo en la Ley 30/1992, de 26 de diciembre, de Régimen Jurídico de las Administraciones Públicas y del Procedimiento Administrativo Común, que prevé que el Estado y las Comunidades Autónomas creen órganos para la cooperación entre ambos, de composición bilateral o multilateral, de ámbito general o sectorial, en aquellas materias en que exista interrelación competencial. Y de ahí surgen las Conferencias Sectoriales y las Comisiones Bilaterales de Cooperación, que ya vienen funcionando con la excepción de las de Madrid y Comunidad Valenciana, cuya constitución es previsible en un futuro próximo.

Pero quiero referirme hoy, por lo novedoso del tema, a una iniciativa gubernamental recientísima, que cabe enmarcar dentro de ese autonomismo cooperativo al que nos venimos refiriendo.

Se trata de la propuesta, ya convertida en proyecto de Ley ${ }^{49}$, de reforma de la Ley Orgánica del Tribunal Constitucional, concretamente de su art. 33, con objeto de permitir legalmente que, en orden a evitar la interposición de un recurso de inconstitucionalidad, las Comisiones Bilaterales de Cooperación adopten acuerdos que, comunicados al Tribunal Constitucional, produzcan el efecto de ampliar el plazo del recurso $y$, mientras tanto, de procurar la correspondiente modificación normativa que evite el recurso.

El Proyecto consiste en añadir dos párrafos al citado art. 33:

- En el primero se indica que, no obstante el plazo de tres meses previsto para interponer el recurso de inconstitucionalidad, el Presidente del Gobierno y los órganos colegiados ejecutivos de las Comu-

47 Vid. J. Tajadura Tejada, El principio de cooperación en el Estado autonómico, E. Comares, Granada, 1998, pág. 9.

48 J. Corcuera Atienza, «Autonomismo cooperativo y autonomismo competitivo: Aquiles y la tortuga", en Sistema, n. ${ }^{\circ} 118-119$, marzo 1994, pág. 87 y ss.

49 Aprobado por el Consejo de Ministros de 9 de julio de 1999. 
nidades Autónomas podrán interponer el recurso en el plazo de 9 meses, contra Leyes, disposiciones normativas y actos con fuerza de Ley en relación con las cuales, y con la finalidad de evitar la interposición del recurso, se haya adoptado un acuerdo en el seno de las Comisiones Bilaterales de Cooperación entre el Estado y las respectivas Comunidades Autónomas.

Para ello, dicho acuerdo debe ponerse en conocimiento del Tribunal Constitucional por los órganos anteriormente mencionados, dentro de los 3 meses siguientes a la publicación de la Ley, disposición o acto con fuerza de Ley, y se insertará en el BOE y en el Diario Oficial de la correspondiente Comunidad Autónoma. Se establece, de este modo, un plazo no tan corto como el de 3 meses, para que se pueda alcanzar un acuerdo al respecto $y$, en caso contrario, formular el correspondiente recurso de inconstitucionalidad.

- El segundo párrafo salva, como es lógico, la facultad de interposición del recurso de inconstitucionalidad por los demás órganos y personas legitimados para ello.

De esta manera, aplicando una técnica eminentemente cooperativa, se conseguirá a buen seguro reducir la conflictividad Estado-Comunidad Autónoma, evitando la interposición de recursos de inconstitucionalidad que tantas tensiones produce en el ámbito de las relaciones entre aquéllos y que colapsan al Tribunal Constitucional50 obligándole a intervenir para resolver lo que puede solventarse extrajurisdiccionalmente.

4. Y por último, es preciso hacer referencia, aún someramente porque será objeto de tratamiento más detallado por el Prof. LópezAguilar, a la cuestión de los hechos diferenciales planteada recientemente por los partidos nacionalistas como reacción a la homogeneización competencial operada en los últimos años.

Que existen hechos diferenciales es algo que se desprende de una simple lectura del texto constitucional.

Pero la tensión que provoca el tema comporta que cada día resulte más apremiante delimitar con precisión los hechos diferenciales y las consecuencias que de su reconocimiento cabe extraer.

50 A 25 de marzo de 1999, el Estado había interpuesto un total de 178 recursos de inconstitucionalidad contra leyes de las Comunidades Autónomas, estando 50 pendientes de Sentencia. Por su parte, las Comunidades Autónomas habian formulado un total de 221 recursos de inconstitucionalidad, de los que 76 aún no han sido resueltos. (Fuente: MAP). 
Coincido con el Prof. Trujillo cuando distingue entre los hechos diferenciales y las aspiraciones diferenciadoras que legítimanente pueden plantearse en el marco de nuestra Constitución. Mientras que los primeros pueden definirse como aquellas diversidades autonómicas constitucionalmente relevantes en tanto que singularidades que, por estar previstas por la Constitución o ser consecuencia directa de previsiones constitucionales, constituyen un límite a la homogeneidad (piénsese en la lengua y cultura propias, en los derechos civiles forales o especiales, en las peculiaridades económico-financieras o en la insularidad), las segundas, las aspiraciones diferenciadoras, son pretensiones tendentes a lograr una acentuación del principio diversificador en favor de una o varias Comunidades Autónomas, aun a costa de acrecentar los perfiles asimétricos del Estado autonómico51.

En mi opinión, no resulta constitucionalmente legítimo la pretensión de un status de privilegio de una Comunidades Autónomas respecto de otras. Las diferencias en el punto de partida no legitiman para perpetuar una situación que la propia Constitución permite superar.

Desde luego, se puede reconocer la asimetría en cualquier modelo de descentralización política, como ocurre en nuestra Constitución, que establece el principio dispositivo. Pero una asimetría no elegida atentaría contra el principio dispositivo $\mathrm{y}$, por tanto, contra la misma Constitución ${ }^{52}$.

Éste es uno de los retos, posiblemente ahora el más relevante, que tiene planteado nuestro Estado autonómico. El desencuentro entre quienes defienden la imposición de una asimetría en su propio beneficio y quienes pretenden el imperio de la voluntariedad, es evidente.

Pero cuando determinadas reivindicaciones exceden de lo que razonablemente cabe entender comprendido en la Constitución, lo correcto constitucionalmente es plantear la reforma constitucional y alcanzar el consenso necesario para ello.

Pero siempre teniendo en cuenta que cualquier pretensión en beneficio de unos pocos perturbaría lo que alguien ha llamado la paz social autonómica.

51 G. TRUJILLo, «Integración constitucional de los hechos diferenciales y preservación de la cohesión básica del Estado autonómico", en Asimetria y cohesión..., cit. pág. 19.

52 Vid. E. Álvarez Conde, op. cit., pág. 87. 